\title{
Comparative dynamic transcriptome analysis (CDTA) reveals mutual feedback between mRNA synthesis and degradation
}

\author{
Mai Sun, ${ }^{1}$ Björn Schwalb, ${ }^{1}$ Daniel Schulz, ${ }^{1}$ Nicole Pirkl, Stefanie Etzold, Laurent Larivière, \\ Kerstin C. Maier, Martin Seizl, Achim Tresch, ${ }^{2}$ and Patrick Cramer ${ }^{2}$ \\ Gene Center Munich and Department of Biochemistry, Center for Integrated Protein Science CIPSM, Ludwig-Maximilians-Universität \\ München, 81377 Munich, Germany
}

\begin{abstract}
To monitor eukaryotic mRNA metabolism, we developed comparative dynamic transcriptome analysis (cDTA). cDTA provides absolute rates of mRNA synthesis and decay in Saccharomyces cerevisiae $(S c)$ cells with the use of Schizosaccharomyces pombe $(S p)$ as an internal standard. CDTA uses nonperturbing metabolic labeling that supersedes conventional methods for mRNA turnover analysis. cDTA reveals that $S c$ and $S p$ transcripts that encode orthologous proteins have similar synthesis rates, whereas decay rates are fivefold lower in $S p$, resulting in similar mRNA concentrations despite the larger $S p$ cell volume. cDTA of $S c$ mutants reveals that a eukaryote can buffer mRNA levels. Impairing transcription with a point mutation in RNA polymerase (Pol) II causes decreased mRNA synthesis rates as expected, but also decreased decay rates. Impairing mRNA degradation by deleting deadenylase subunits of the Ccr4-Not complex causes decreased decay rates as expected, but also decreased synthesis rates. Extended kinetic modeling reveals mutual feedback between mRNA synthesis and degradation that may be achieved by a factor that inhibits synthesis and enhances degradation.
\end{abstract}

[Supplemental material is available for this article.]

Cellular gene expression is controlled by mRNA levels, which are governed by the rates of nuclear mRNA synthesis and cytoplasmic mRNA degradation. The rates of mRNA synthesis are regulated during RNA polymerase (Pol) II transcription in the nucleus (Fuda et al. 2009), whereas bulk mRNA degradation occurs in the cytoplasm (Eulalio et al. 2007; Parker and Sheth 2007; Wiederhold and Passmore 2010). During transcription, the mRNA receives a $5^{\prime}$-cap and a 3 '-poly(A) tail. The mature mRNA is then exported to the cytoplasm, translated, and eventually degraded cotranslationally (Hu et al. 2009). Cytoplasmic mRNA degradation generally begins with shortening of the poly(A) tail by the Ccr4-Not complex, which contains the deadenylases Ccr4 and Pop2 (also known as Caf1) (Liu et al. 1998; Tucker et al. 2001). The mRNA is then decapped and degraded by exonucleases from both ends. Despite the spatial separation of mRNA synthesis and translation/degradation, there is evidence that these processes are coordinated (Lotan et al. 2005; Lotan et al. 2007; Harel-Sharvit et al. 2010).

To investigate coordinated RNA synthesis and degradation, absolute changes in synthesis and decay rates must be measured after introducing a genetic perturbation that impairs either synthesis or degradation. Rates of mRNA synthesis and degradation can be measured by dynamic transcriptome analysis (DTA) in yeast (Miller et al. 2011). Newly synthesized RNA is labeled with 4-thiouridine $(4 \mathrm{sU})$, which is taken up by cells that express a nucleoside transporter. After 6 min of labeling, total RNA is extracted and separated into newly synthesized (labeled) and pre-existing (unlabeled) fractions. Total, labeled, and unlabeled fractions are analyzed with microarrays and the data are fitted with a dynamic kinetic model to extract

\footnotetext{
'These authors contributed equally to this work.

${ }^{2}$ Corresponding authors

E-mail tresch@LMB.uni-muenchen.de

E-mail cramer@LMB.uni-muenchen.de

Article published online before print. Article, supplemental material, and publication date are at http://www.genome.org/cgi/doi/10.1101/gr.130161.111.
}

synthesis and decay rates. Whereas DTA accurately measures the relative rates for different RNAs within a single sample, it cannot compare rates from different samples, since the samples differ by an unknown global factor (Miller et al. 2011). In standard transcriptomics, comparison between samples with different mRNA levels may be achieved by counting cells and spiking RNA standards into the samples (Holstege et al. 1998; Wang et al. 2002; van de Peppel et al. 2003). However, such normalization does not take into account differences in cell lysis and RNA extraction efficiency, which can vary so strongly that no conclusions are possible.

To enable normalization between DTA measurements of different samples, we extended DTA to comparative DTA (cDTA). In cDTA, a defined number of labeled fission yeast Schizosaccharomyces pombe $(S p)$ cells is added to the budding yeast Saccharomyces cerevisiae $(S c)$ sample before cell lysis and RNA preparation, and is used as an internal standard. Thereby, cDTA allows the absolute quantification and accurate comparison of mRNA synthesis and decay rates between samples. cDTA is a novel method that monitors absolute changes in eukaryotic mRNA metabolism upon genetic perturbation. We applied cDTA to $S c$ cells that are impaired in either mRNA synthesis or degradation. This revealed compensatory changes in degradation and synthesis, respectively, which indicates that a eukaryote can buffer mRNA levels to render gene expression robust. After our work was completed, an independent study appeared that postulates a similar compensation on an evolutionary scale (Dori-Bachash et al. 2011).

\section{Results}

\section{Comparative dynamic transcriptome analysis (cDTA)}

To measure changes in mRNA synthesis and decay rates between different strains of budding yeast $(S c)$, we included the distantly related fission yeast $(S p)$ in our DTA protocol as an internal standard (Fig. 1). We counted $S c$ sample cells and $S p$ control cells and 


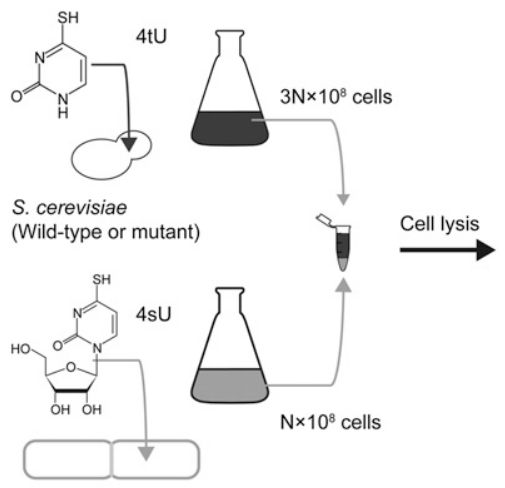

S. pombe (internal standard)

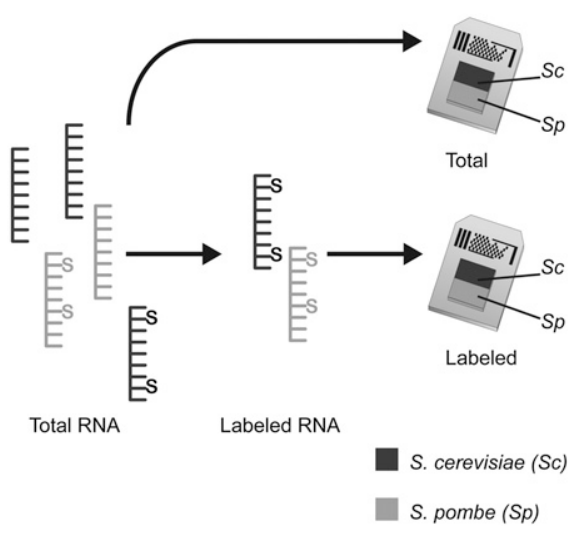

Figure 1. Design of a cDTA experiment. The $S c$ cells are labeled by adding $4 \mathrm{tU}$ into the media, whereas Sp cells are labeled by adding $4 \mathrm{sU}$. The cells are then counted. SC cells from different experiments are always mixed with the same amount of labeled Sp cells from a single batch. Cells are then lysed, RNA is extracted, biotinylated, and labeled RNA separated. Microarrays containing probes against both Sc and Sp transcripts are then used to quantify both total and labeled RNA.

mixed them in a defined ratio (Methods). The resulting cell mixture was lysed, total mRNA extracted, labeled RNA purified, and microarrays were hybridized as described (Miller et al. 2011). The RNA mixture was quantified on a microarray that contains probes for both $S c$ and $S p$ transcripts (Affymetrix GeneChip Yeast Genome 2.0 Array) (Miller et al. 2011). We used 4-thiouracil (4tU) instead of $4 \mathrm{sU}$ for $S c$ RNA labeling, because it is taken up by $S c$ (Munchel et al. 2011) without expression of a nucleoside transporter (Miller et al. 2011). 4tU labeling did not affect normal cell physiology (Supplemental Fig. S1) and allowed growth of yeast in YPD instead of selective medium. We quantified only labeled and total RNA, because the unlabeled fraction was not required for rate extraction. We refer to this protocol as comparative DTA (cDTA).

We first tested whether the $S c$ sample showed cross-hybridization to $S p$ array probes and vice versa. When either a $S c$ or $S p$ sample was hybridized to the array, cross-hybridization occurred for a minor fraction of the probes (Methods) when a conservative intensity cut-off of 4.5 (log intensity values after preprocessing) was used (Fig. 2A). Cross-hybridizing probes were excluded from further analysis, leading to loss of only 16 out of 10,799 probe sets (Methods). The mixing ratio of $S c: S p$ cells was tuned to 3:1 to maximize the overlap of the $S c$ and $S p$ expression intensity distributions (Fig. 2B). This ensures that after calibration most $S c$ and $S p$ probe intensities are in the linear measurement range of the microarray, an important prerequisite for our calculations. We restricted our analysis to RNAs with log intensity signals above 4.5 and below 8 (Fig. 2B).

\section{Rate extraction from cDTA data}

To obtain absolute synthesis and decay rates for $S c$ and $S p$, we derived the ratios of labeled to total RNA intensities $\mathrm{c}_{S c}$ and $\mathrm{c}_{S p}$ for $S c$ and $S p$, respectively. These ratios set the global median level of synthesis and decay rates and rely on a robust previous estimate of the median Sc half-life (Miller et al. 2011) for which labeled, total, and unlabeled RNA fractions were available. Once $c_{s p}$ is known, the measured levels of the $S p$ standard can be used to calibrate the $S c$ data (Fig. 3A). This new normalization method allows rate estimation from labeled and total quantities alone (Methods). Our published median half-life for $S c$ mRNAs (Miller et al. 2011) enabled determination of the median $S p$ half-life relative to $S c$ (Supplemental Fig. S2). We measured growth curves and obtained a doubling time of $90 \mathrm{~min}$ for $S c$ in YPD medium at $30^{\circ} \mathrm{C}$ and $116 \mathrm{~min}$ for $S p$ in YES medium at $32^{\circ} \mathrm{C}$ (Supplemental Fig. S3). These doubling times were used in kinetic modeling (Miller et al. 2011). We confirmed that the rates obtained by cDTA are essentially the same as the ones previously obtained by DTA (Table 1; Supplemental Fig. S2). RNA halflives that were recently determined by $4 \mathrm{tU}$ pulse-chase labeling in $S c$ are 1.5 -fold longer (Munchel et al. 2011), likely because a very long labeling time was used that allowed for thionucleotide reincorporation after mRNA decay. We calculated mRNA synthesis rates as the number of complete transcripts made per cell and per $90 \mathrm{~min}$ (the cell cycle time for wild-type $S c$ ), using a new estimate of 60,000 transcripts per yeast cell (Zenklusen et al. 2008) instead of the previously used, older, and fourfold lower estimate (Hereford and Rosbash 1977). For $S p$, we estimated the number of transcripts from the observed 2.51-fold cumulative total RNA level to be 150,801. Our rate estimates are unaffected by the efficiency of $4 \mathrm{tU}$ labeling, which varies between strains and experiments (Supplemental Fig. S1).

For normalization between different $S c$ samples, we linearly rescaled all array intensities such that the total and labeled $S p$ fractions have a median intensity of 1 or $\mathrm{c}_{S p}$ (Fig. 3B). We assessed the accuracy of the cDTA procedure by estimating the intensity ratios of $S c: S p$ cells that were mixed at 1:1, 3:1, and 10:1. The correct values were recovered with an accuracy of 5\% (Fig. 2D). Selected mRNA levels of the 1:1 and 10:1 ratio mixtures were additionally quantified by RT-qPCR (Methods). The expected ratio of the four tested $S c$ transcripts was recovered within a relative error of $9 \%$ when normalized to two housekeeping $S p$ genes (data not shown). In summary, cDTA normalization removes the major sources of experimental differences between samples in RNA-labeling efficiency, cell lysis, RNA extraction, RNA biotinylation and labeled RNA purification, and array hybridization. cDTA detects global changes between $S c$ samples, in contrast to standard normalization procedures that eliminate global changes, because they assume constant median RNA levels.

\section{cDTA supersedes conventional methods}

Conventional methods measure mRNA half-lives by inducing transcription arrest and following changes in mRNA levels over time. Transcription arrest has been achieved by adding the transcription inhibitor 1,10-phenanthroline (Dori-Bachash et al. 2011) or by shifting the temperature-sensitive mutant strain rpb1-1, which carries point mutations in the largest subunit of Pol II (Nonet et al. 1987), to the restrictive temperature (Holstege et al. 1998; Wang et al. 2002; Grigull et al. 2004; Shalem et al. 2008). To investigate whether the latter method yields reliable data or whether it perturbs mRNA metabolism, we regenerated the rpb1-1 strain and analyzed it with cDTA using published growth parameters (Holstege et al. 1998) (Methods). This revealed that mRNA synthesis rates were decreased globally by a factor of 2.7 already at the permissive temperature of $30^{\circ} \mathrm{C}$ (Fig. 4A). After $24 \mathrm{~min}$ at the restrictive temperature, mRNA synthesis rates had decreased further by a factor of 3.4, but recovered essentially to the rates measured at the permissive temperature after 66 min (Fig. 4A).

These observations indicated that the mRNA metabolism in the $r p b 1-1$ strain is already perturbed at the permissive temperature, and that the temporary changes in mRNA metabolism ob- 
A

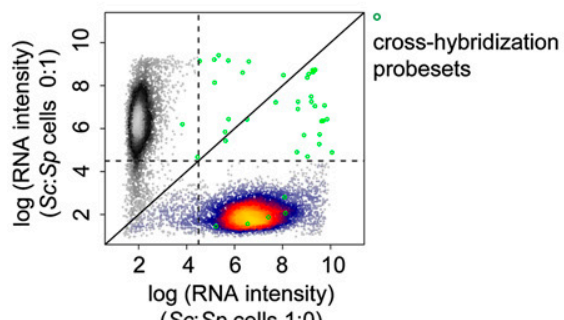

C

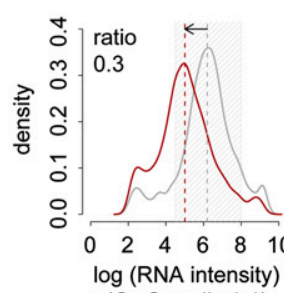
(Sc:Sp cells 1:1)

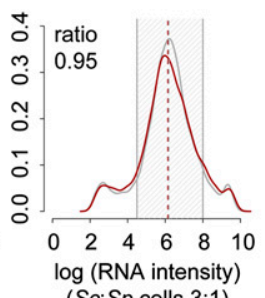
(Sc:Sp cells 3:1)
B
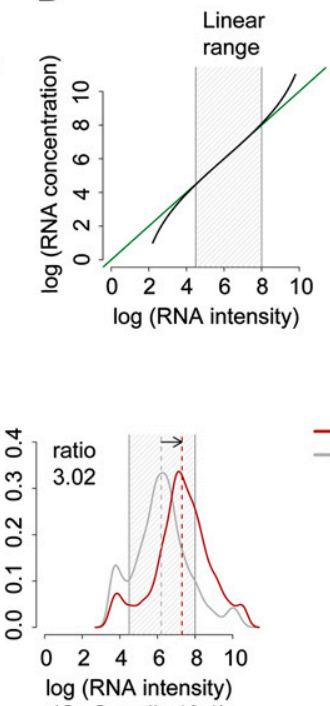

(Sc:Sp cells 10:1)

D
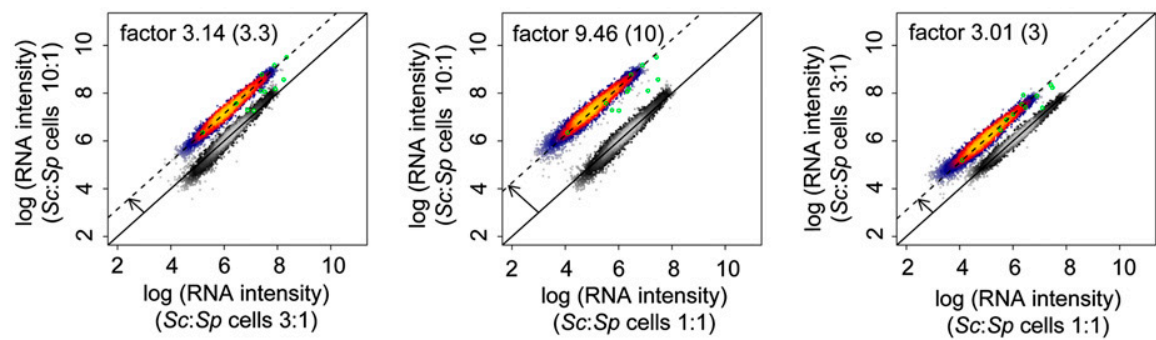

Figure 2. Establishing the CDTA protocol. (A) Assessment of cross-hybridization. Scatterplot of log intensities of 10,928 Affymetrix probe sets. The values on the $x$-resp. $y$-axis are obtained as the mean of two pure $S c$ resp. Sp replicate samples that were hybridized to the arrays. $S c$ and $S p$ probe sets (heat colored and gray scaled, respectively) can be separated almost perfectly. A total of 23 out of 5771 SC probe sets show intensities above a (log) background intensity threshold of 4.5 in the $S p$ sample, whereas eight out of 5028 Sp probe sets were above background in the Sc sample. These 31 probe sets are regarded as affected by cross-hybridization (green circles). Of these, 16 probe sets were excluded from analysis because all probes were affected by cross-hybridization (Methods). (B) Linear measurement range. Exemplary illustration showing that the relation of mRNA concentration (real amount) and mRNA intensity (fluorescent scanner readout) follows the Langmuir adsorption model (Hekstra et al. 2003; Held et al. 2003, 2006; Skvortsov et al. 2007). The green line indicates linearity. (Black line) Sigmoidal behavior, resulting from noise at low-hybridization levels and saturation effects at highhybridization levels. (Gray stripe) Linear measurement range that we defined as an intensity range of 4.5-8 (natural log basis) based on noise signals below 4.5, for example, for probes that detect transcripts of genes that were knocked out and based on observed saturation effects above 8. (C) Calibration of $S c: S p$ cell mixture ratio. The optimal cell mixture ratio has been chosen to maximize the number of probes for both $S c$ and $S p$ that fall into the linear measurement range $(B) . S C$ and $S p$ cells were mixed in $S c: S p$ ratios of 1:1, 3:1, and 10:1. The respective median mRNA level ratios are 0.3, 0.95, and 3.02. Log (RNA intensity) distributions of $S c$ (red) and $S p$ (gray) are shown. The median intensity level of $S p$ is approximately three times higher than that of $S c$. As a consequence, a $S c: S p$ cell mixture ratio of 3:1 was used. $(D)$ Comparison of the three different cell mixtures of $(C)$ in pairwise log-log scatter plots. All arrays are normalized to a common median of $4052 \mathrm{Sp}$ probe sets (gray-scaled). A total of $4475 \mathrm{Sc}$ probe sets (those in the linear measurement range) are shown in heat colors. The parallel offset of the Sc probe sets from the main diagonal measures the mRNA level differences of $S c$ in the three cell mixtures. The differences should be $3.3,10$, and 3 when we plot $S c: S p$ ratios of $10: 1$ vs. $3: 1,10: 1$ vs. 1:1, and $3: 1$ vs. $1: 1$, respectively. The corresponding measured offsets are $3.14,9.46$, and 3.01 , and thus in very good agreement.

served at the restrictive temperature are mainly due to a heat-shock response. To test this, we conducted a corresponding heat-shock experiment on wild-type cells. We analyzed the total mRNA from this experiment together with the data from the rpb1-1 mutant by conventional decay time series analysis (Holstege et al. 1998; Wang et al. 2002; Grigull et al. 2004; Shalem et al. 2008). The obtained mRNA half-lives during heat shock correlated very well with data

derived from the rpb1-1 mutant strain and with published half-lives obtained with this strain (Fig. 4B). The obtained half-lives were longer than the half-lives measured in unperturbed cells, likely because mRNA degradation was down-regulated during the stress response. There was also a good correlation with half-lives obtained after adding 1,10-phenanthroline and even with our previous data obtained during the osmotic stress response (Miller et al. 2011), if processed in the conventional way. This indicates that all of these data are dominated by perturbations in mRNA metabolism that result from a general stress response. In contrast, published half-lives derived from metabolic RNA labeling (Munchel et al. 2011) and our CDTA-derived half-lives do not correlate with data obtained by perturbing conventional methods. We conclude that conventional methods for estimating mRNA half-lives using the $r p b 1-1$ mutant strain or transcription inhibition cannot be used to obtain reliable half-life estimations.

\section{Comparison of mRNA metabolism in distant yeast species}

As an immediate result, cDTA reveals similarities and differences in the mRNA metabolism of $S c$ and $S p$. First, the median mRNA synthesis rates are very similar in $S c$ and $S p$ (Fig. 5A). The median synthesis rate was $53 \mathrm{mRNAs}$ per cell and $90 \mathrm{~min}$ for wild-type $S c$, and 44 mRNAs per cell and $90 \mathrm{~min}$ for $S p$. Second, $S p$ mRNAs have about fivefold longer half-lives on average than $S c$ mRNAs, with a median of 59 min (Fig. 5A; Supplemental Fig. S4), compared with 12 min for $S c$. As expected, the cDTA-derived $S p$ half-lives show a fair correlation with half-lives obtained by another nonperturbing metabolic labeling (Amorim et al. 2010). Furthermore, reprocessing the data of Amorim et al. (2010) with our cDTA algorithm, which takes into account the labeling bias and an additional parameter to correct for cell growth, increases the correlation to our results and leads to a median half-life of $50 \mathrm{~min}$, in good agreement with an estimate of 59 min in our study (Supplemental Fig. S2). Third, the overall mRNA levels in $S p$ were about 3.1-fold higher than in $S c$. Since the haploid $S c$ cells with a median volume of $42 \mu \mathrm{m}^{3}$ are approximately two- to threefold smaller than $S p$ cells with a median cell volume of $\sim 115 \mu \mathrm{m}^{3}$ (Jorgensen et al. 2002; Neumann and Nurse 2007), the higher mRNA levels apparently lead to similar cellular mRNA concentrations. The change in mRNA levels is mainly a global multiplicative change $\left(\mathrm{R}^{2}=0.82\right.$, Supplemental Fig. S4). 
A

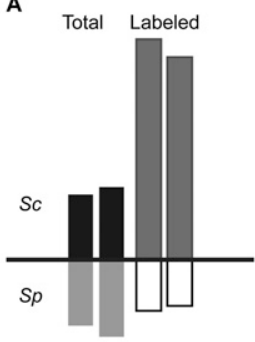

B

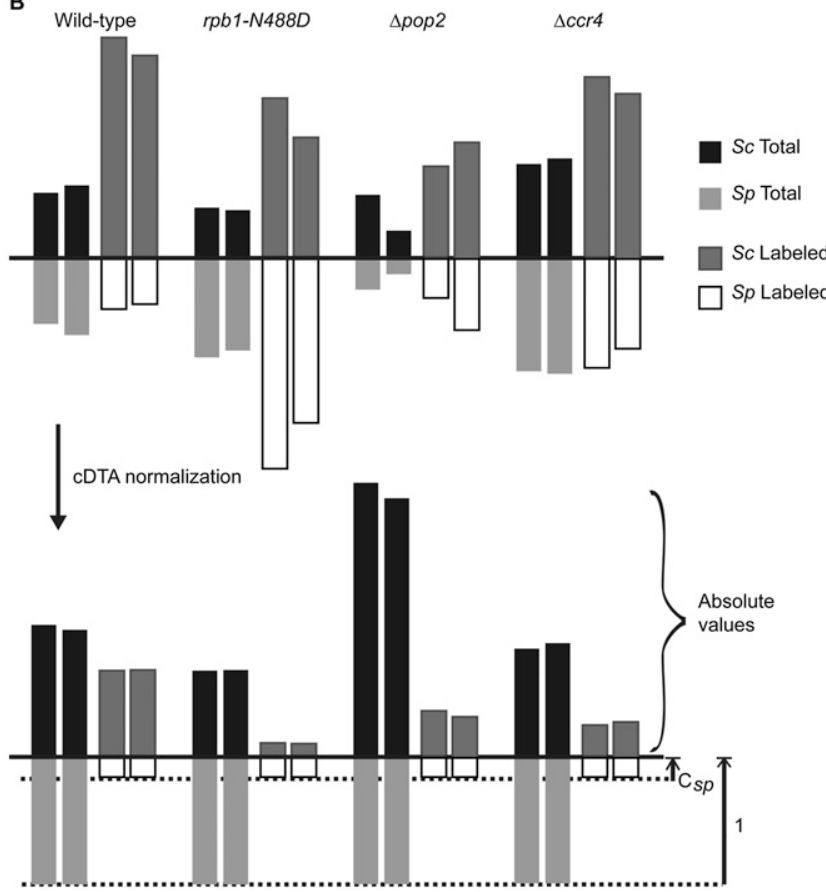

Figure 3. cDTA normalization reveals global changes. $(A)$ Determination of $c_{s p}$, the ratio of labeled over total $S p$ mRNA. To obtain absolute synthesis and decay rates for $S c$ and $S p$, we derived ratios of labeled to total RNA $c_{S c}$ and $c_{S p}$ for $S c$ and $S p$, respectively. The $c_{S c}$ ratio was obtained in our previous study (Miller et al. 2011). To determine $c_{s p}, L_{s c}$ and $T_{s c}$ are set to $C_{s c}$ and 1 , respectively. $L_{s p}$ and $T_{s p}$ are then linearly rescaled. The resulting $L_{s p} / T_{s p}$ is defined as $C_{s p}$ and then used in the further experiments as the global CDTA normalization factor. (B) CDTA normalization uses $S p$ signals as an internal standard. The bars indicate the median intensities of the array probe sets. Due to our experimental design, the ratio of labeled to total $S p$ RNA $\left(c_{S p}=L_{s p} / T_{s p}\right)$ must be the same in all experiments. To correct for differences in cell lysis, RNA extraction efficiency, and RNA purification efficiencies, the levels of $S p$ total and labeled mRNA are rescaled to the same values in all experiments. The Sc RNA levels are then corrected by median centering of $S p$ RNA levels. This normalization allows for a direct comparison of Sc data between experiments. Shown are both replicates for each of the four CDTA experiments.

Taken together, these data suggest that $S p$ cells generally contain more stable mRNAs than $S c$ cells to reach similar mRNA concentrations at similar mRNA synthesis rates, despite their larger volume.

We investigated whether mRNA sequence conservation correlates with a conservation of total RNA levels, synthesis rates, or decay rates (Fig. 5B; Supplemental Fig. S4). This analysis revealed a conservation of the relative total levels of mRNAs that encode orthologous proteins in $S c$ and $S p$. The levels of mRNAs that encode proteins with an amino acid sequence identity of at least $25 \%$ (2568 mRNAs) show a high Spearman correlation of 0.69. Synthesis rates correlate well between both species (Spearman correlation 0.61), but the half-lives show only a fair correlation (Spearman correlation 0.4). Although the data suggest that $S p$ cells have globally shifted decay rates, to reach similar cellular mRNA concentrations, there is a minor fraction of transcripts that behave exceptionally. In particular, $93 S p$ transcripts show almost unchanged mRNA levels ( $<1.5$-fold), but significantly higher synthesis and decay rates ( $>1.5$-fold), and are enriched for ribosomal protein genes (Fig. 5A). More generally, transcripts that encode highly conserved proteins show similar levels, but a faster turnover in $S p$ (Fig. 5B). We also assessed the correlation of synthesis rates with transcript lengths, and revealed a substantially higher Pol II drop-off rate in $S p$ (Supplemental Fig. S5).

\section{Impaired mRNA synthesis is compensated by decreased degradation}

We applied cDTA to the question of whether the speed of Pol II is relevant for setting the cellular rates of mRNA synthesis. We used a yeast strain that carries the nondisruptive point mutation N488D in the largest Pol II subunit Rpo21 (also known as Rpb1) (rpb1$N 488 D$ ). This mutation slows down Pol II speed in RNA elongation assays in vitro (Malagon et al. 2006) and is located near the active site (Cramer et al. 2001). We subjected this strain and an isogenic wild-type strain to cDTA, and collected two biological replicates that showed a Spearman correlation of 0.99 for total and labeled

Table 1. Median mRNA half-lives and synthesis rates of $S c$ and $S p$ transcripts

\begin{tabular}{lccc}
\hline & Species & cDTA & DTA \\
\hline Median mRNA half-life (min) & $S c$ & 12 & 11.5 \\
& $S p$ & 59 & N.A. \\
Median mRNA synthesis rate & $S c$ & $53^{\mathrm{a}}$ & $18(72)^{\mathrm{a}}$ \\
(mRNAs per cell and cell cycle time) $^{\mathrm{a}}$ & $\mathrm{Sp}$ & 44 & N.A. \\
\hline
\end{tabular}

The CDTA contains the estimates obtained from using the labeled:total ratio of the complementary strain and the known total and labeled $S c: S p$ ratios to calculate the missing labeled:total ratio, i.e., $L_{S c} / T_{S c}=\left(L_{S p} / T_{S p}\right) \cdot\left(T_{S p} / T_{S c}\right) \cdot\left(L_{S c} / L_{S p}\right)$. The DTA column shows the $S c$ half-life estimate obtained from Miller et al. (2011). Note that the Sc estimates are virtually identical to ours, although we used a different labeling technique (4tU instead of $4 \mathrm{~s} U$ ) and had spiked-in Sp controls in the sample. aplease note that we previously used in our calculations a total number of transcripts per cell of 15,000 according to an old estimate (Hereford and Rosbash 1977), whereas we now used a recent estimate of 60,000 (Zenklusen et al. 2008). If the same number of transcripts is used, the median synthesis rate obtained by DTA would be 72 , comparable to our new estimate obtained by CDTA, despite the difference in media and cell cycle time (Miller et al. 2011). 
A

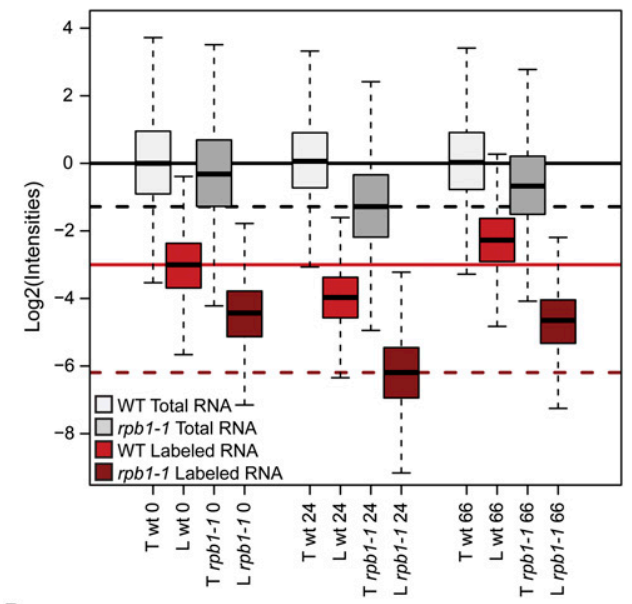

B

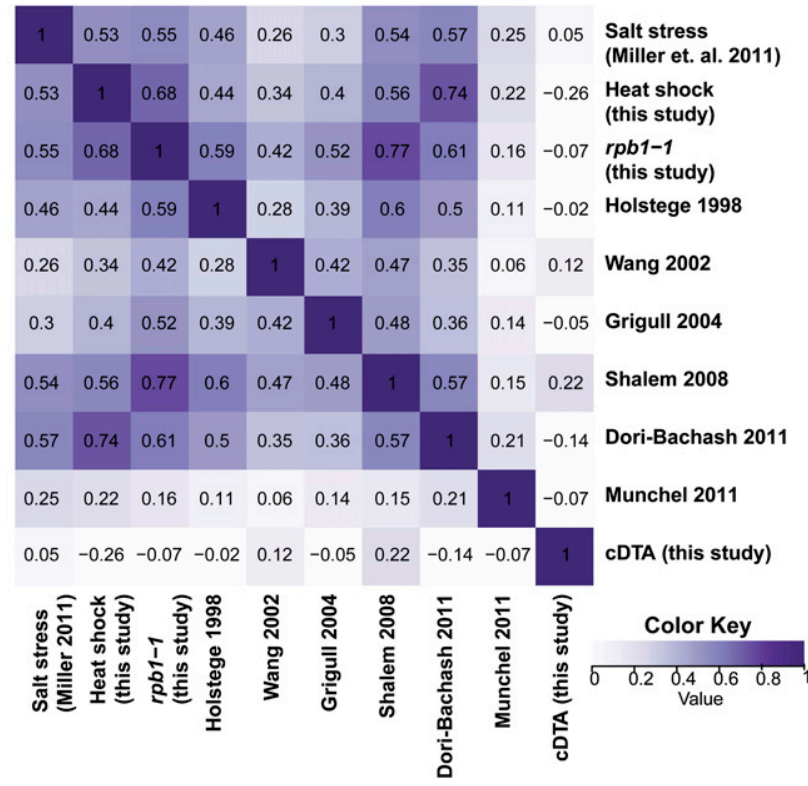

Figure 4. Comparison of CDTA with conventional methods. (A) Box plots of the expression distributions of the total and the labeled (newly synthesized) mRNA after CDTA normalization, obtained from the wildtype and the rpb1-1 mutant before, and 24 and 66 min after the shift to restrictive temperature. Transcriptional activity is roughly restored in both strains after $66 \mathrm{~min}$. The global shifts in labeled expression are only slightly more pronounced in the rpb1-1 mutant, indicating a dominant role of heat shock in the profiles of rpb1-1. (B) Correlation analysis of mRNA halflife measurements. The heatmap shows pairwise Spearman correlation coefficients of half-life measurements (white: negative or zero correlation purple: perfect correlation). The published half-life estimates except for Munchel et al. (2011) were obtained by experiments using transcriptional arrest. The estimates of Holstege et al. (1998), Wang et al. (2002), Grigull et al. (2004), and Shalem et al. (2008) were obtained using a yeast strain containing the Pol II temperature sensitive mutant rpb1-1. Dori-Bachash et al. (2011) used the transcription inhibitor 1,10-phenanthroline.

RNA (Supplemental Fig. S6). We measured cell-doubling times, and used these in the kinetic modeling to correct synthesis rates for a change in doubling time (Supplemental Fig. S3). In the rpb1N488D mutant strain, mRNA synthesis rates were globally decreased 3.9-fold (Fig. 6A). This is consistent with the observed twoto 4.5 -fold decrease in Pol II speed measured in vitro (Malagon et al.
2006). We observed a Pol II drop-off rate similar to that described previously (Jimeno-González et al. 2010), but quantitative modeling excludes drop-off of Pol II during elongation as the cause for the decreased synthesis rates (Supplemental Fig. S7).

Despite the lower synthesis rates, global mRNA levels were not changed very much in the slow Pol II mutant strain (Fig. 6A). This resulted from a strong decrease in mRNA decay rates of 3.2-fold on average. Synthesis and decay rates of all mRNAs were shifted by approximately the same factor, independent of their wild-type expression level, synthesis rate, or decay rate. The globally increased mRNA half-lives apparently compensated for the decreased mRNA synthesis rates to buffer cellular mRNA levels, which were decreased 1.3-fold only. The measured total RNA levels agreed well with total mRNA levels calculated from the changed synthesis and decay rates (Fig. 6B,C). These results show that cells with a strong defect in mRNA synthesis can maintain nearly normal mRNA levels by compensatory changes in mRNA decay rates.

\section{Impaired degradation is compensated by decreased synthesis}

The observed synthesis-decay compensation implies that cells buffer total mRNA levels. If true, cells should also be able to compensate for a mutation that impairs mRNA degradation with a change in mRNA synthesis rates. To investigate this, we applied cDTA to mutant yeast strains with global defects in mRNA degradation. The choice of mutant was difficult, since RNA degradation involves multiple enzymes in the nucleus and cytoplasm (Houseley and Tollervey 2009). We decided to use mutant strains that lack either one of the two catalytic subunits of the Ccr4-Not complex, Ccr4 or Pop2, which show a defect in mRNA deadenylation, a ratelimiting step in mRNA degradation (Tucker et al. 2002). As predicted, mRNA decay rates were globally decreased in the $\Delta c c r 4$ and $\Delta p o p 2$ strains, and changed on average by a factor of 0.43 and 0.16 , respectively (Fig. 6C). This suggests that Ccr4 and Pop2 mRNA degradation factors are used globally.

In both degradation-deficient knock-out strains, an unexpected decrease in mRNA synthesis rates was observed (Fig. 6C). Synthesis rates were changed by a factor of 0.49 and 0.38 in the $\Delta c c r 4$ and $\Delta p o p 2$ strains, respectively, limiting the increase in total mRNA levels due to highly defective degradation to a factor of only 1.18 and 1.75, respectively (Fig. 6C). This effect could be observed directly in the labeled fractions of the $\Delta c c r 4$ and $\Delta p o p 2$ strains. Only $62 \%$ or $46 \%$ of the RNA was labeled within the same labeling time, indicating lower synthesis rates. Thus, the defects in RNA degradation in these strains are at least partially compensated by decreased mRNA synthesis rates in order to buffer mRNA levels. This mutual compensation cannot be explained by measurement variance. A variation analysis for the estimation of the median synthesis and decay rates (Fig. 6D; Supplemental Methods S9) shows that the $95 \%$ confidence regions of the median synthesis and decay rate estimates are clearly disjoint.

\section{A transcription inhibitor and degradation enhancer may buffer mRNA levels}

The above data show that yeast cells can compensate for impaired mRNA synthesis with decreased mRNA decay rates, and for impaired degradation by decreased mRNA synthesis rates. Yeast cells thus have mechanisms to buffer mRNA levels by mutual negative feedback between nuclear mRNA synthesis and cytoplasmic mRNA decay. To explore this further, we extended our model for mRNA turnover under steady-state conditions. The mRNA of 
A

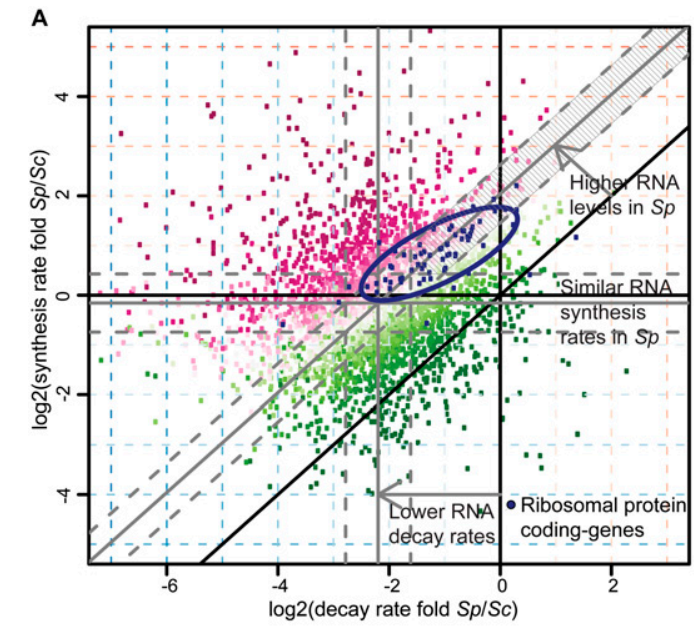

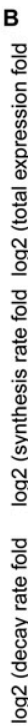
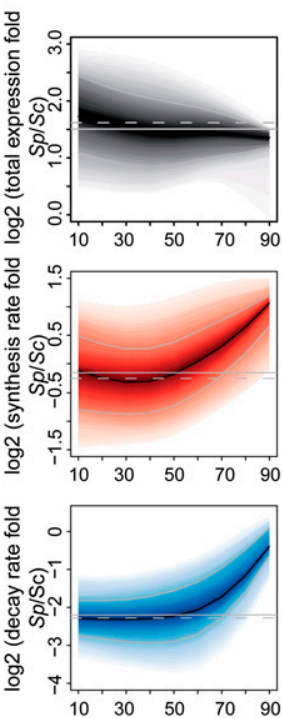

Amino acid sequence identity (\%)

Figure 5. Comparison of mRNA metabolism in $S p$ and $S c$. (A) Scatter plot comparing mRNA decay rate folds versus synthesis rate folds of $S p$ and $S c$ transcripts encoding protein orthologs ( $>25 \%$ amino acid sequence identity). The offset of gray lines to parallel black lines indicates $S p: S c$ ratios of median decay rates, synthesis rates, or total mRNA (0.20/0.83/2.72). Dashed gray lines indicate 1.5-fold changes from the median (gray lines). Color scheme corresponds to folds in total mRNA (magenta, positive log fold; green, negative log fold). A set of genes that show higher decay and synthesis rates (1.5-fold and adjusted $P$-value $0.5 \%)$, but almost unchanged $(<1.5$-fold) total mRNA ( 93 transcripts, striped area) was selected and tested with a Bayesian network-based gene-set analysis (MGSA) (Bauer et al. 2010). In this gene set, the ribosomal protein genes were enriched (blue dots; ellipse shows the $75 \%$ region of highest density). (B) Plots show $\log _{2}$ fold distributions of total mRNA (gray), synthesis rate (red), and decay rate (blue) of $S p$ versus $S c$ transcripts encoding orthologous proteins as a function of amino acid sequence identity (\%). Transcripts encoding highly conserved proteins such as ribosomal proteins are located on the right. They show more rapid turnover (synthesis and decay) in Sp, resulting in similar mRNA levels. (Solid black lines) Median $\log _{2}$ fold; (shaded bands) central $80 \%$ regions. (Solid/ dashed gray lines) Median $\log _{2}$ fold of all orthologs/all genes.

a gene $\mathrm{G}$ is synthesized at a gene-specific constant rate $\mu_{g}$, and is degraded at a gene-specific rate $g \cdot \lambda_{g}$, with $g$ being the mRNA amount resulting from gene $G$. We assume that there is a transcription modulator $S$ and a degradation modulator $D$ that globally affect the synthesis rate (SR) and decay rate (DR) by factors $f(s)$ and $h(d)$, respectively:

$$
\frac{d g}{d t}=S R(g, s)-D R(g, d)=\mu_{g} \cdot f(s)-g \lambda_{g} \cdot h(d) .
$$

The important and plausible assumption of this model is that $f$ and $h$ are monotonic functions. However, we do not assume that mRNA levels translate linearly into protein levels, or that the degree of modulation is a linear function of the underlying mRNA concentrations of $S$ and $D$. One might think of $S$ and $D$ as proteins, whose activity is a function of their mRNA concentrations $s$ and $d$.

From the model (1), we inferred the regulatory logic of the observed feedback, as outlined below. A rigid derivation and an extensive discussion of the model's assumptions are given (Methods; Supplemental Method S8). Here, we compare synthesis and decay rates of a gene between two conditions $C_{\text {and }} \mathrm{C}^{\prime}$ :

$$
\begin{gathered}
\frac{S R^{\prime}\left(g^{\prime}, s^{\prime}\right)}{S R(g, s)}=\frac{\mu_{g}^{\prime} f\left(s^{\prime}\right)}{\mu_{g} f(s)}, \\
\frac{D R^{\prime}\left(g^{\prime}, s^{\prime}\right)}{D R(g, s)}=\frac{g^{\prime} \lambda_{g}^{\prime} h\left(d^{\prime}\right)}{g \lambda_{g} h(d)} .
\end{gathered}
$$

The left-hand sides of Equations (2) and (3) can be evaluated by cDTA. The left-hand side of Equation (2) is substantially smaller than 1 for virtually all measurements $g, g^{\prime}$, and for both deadenylation mutants (Fig. 6B). For these mutants, we also know that $\mu_{g}=\mu_{g}^{\prime}$, and consequently $f\left(s^{\prime}\right)<f(s)$. We also observe that $g^{\prime}>g$ and $s^{\prime}>s$, from which we conclude that $f$ is monotonically decreasing. This implies that $S$ acts as a transcription inhibitor. In the slow Pol II mutant, we observe $\lambda_{g}=\lambda^{\prime}{ }_{g}$. Using a similar argument as above, Equation (3), and cDTA data of the slow Pol II mutant, we conclude that $h$ is monotonically increasing, implying that $\mathrm{D}$ is a degradation enhancer. These conclusions could only be derived because cDTA enables the comparison of global synthesis and decay rates. The results would be identical if $S$ and $D$ were the same molecule. Thus, the most simple explanation of our observations is the existence of a factor that serves as an inhibitor of transcription and an enhancer of degradation and shuttles between the nucleus and cytoplasm.

\section{Discussion}

A systemic investigation of gene expression requires quantitative monitoring of cellular mRNA metabolism. In particular, a technique is required to quantify absolute mRNA synthesis and decay rates on a genome scale upon genetic perturbation. Here, we provide such a technique, which we refer to as comparative dynamic transcriptome analysis (cDTA). cDTA is based on nonperturbing metabolic RNA labeling in mutant and wild-type budding-yeast cells and the use of fission yeast cells as an internal standard. cDTA is a nonperturbing method for monitoring mRNA turnover and supersedes conventional methods, which require transcription inhibition, resulting in a stress response and perturbation of mRNA metabolism.

cDTA improves our previous DTA protocol (Miller et al. 2011) in several respects. First, cDTA provides reliable estimates of the absolute synthesis and decay rates, thereby allowing for a direct comparison of rates between different yeast strains. Second, cDTA uses $4 \mathrm{tU}$ instead of $4 \mathrm{sU}$ for RNA labeling, allowing for standard media and abolishing the need for a nucleoside transporter. Third, cDTA requires only two instead of three microarray measurements per rate estimation. As an immediate result, cDTA revealed that $S p$ and $S c$ cells have similar synthesis rates, but $S p$ RNAs have about fivefold longer mRNA half-lives, leading to similar cellular mRNA concentrations despite a different cell volume.

Application of cDTA to $S c$ cells expressing a Pol II point mutant that elongates mRNA slowly in vitro showed that mRNA elongation is a critical determinant for mRNA synthesis in growing cells in vivo. It also revealed that cells compensate for low synthesis rates by lowering decay rates, thus stabilizing mRNAs and buffering their levels. Application of cDTA to two mutant strains that lack 

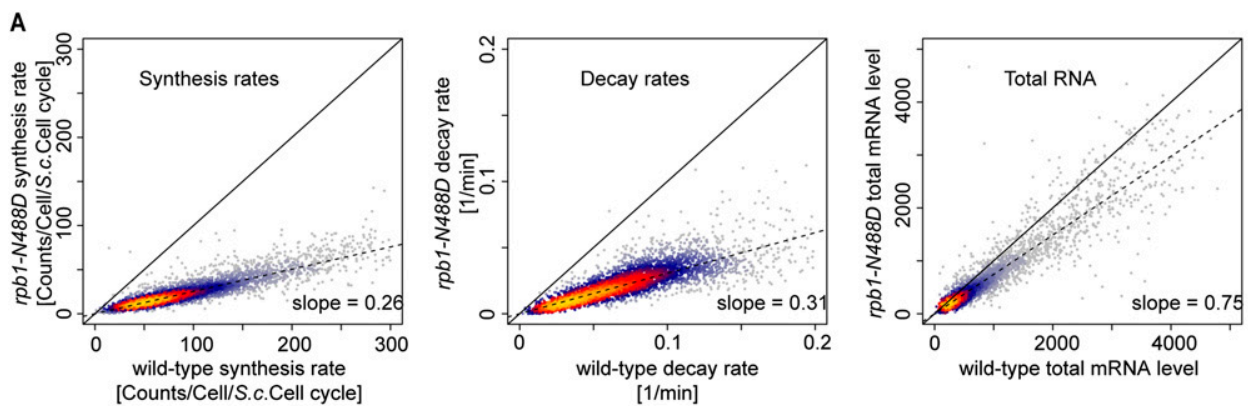

B
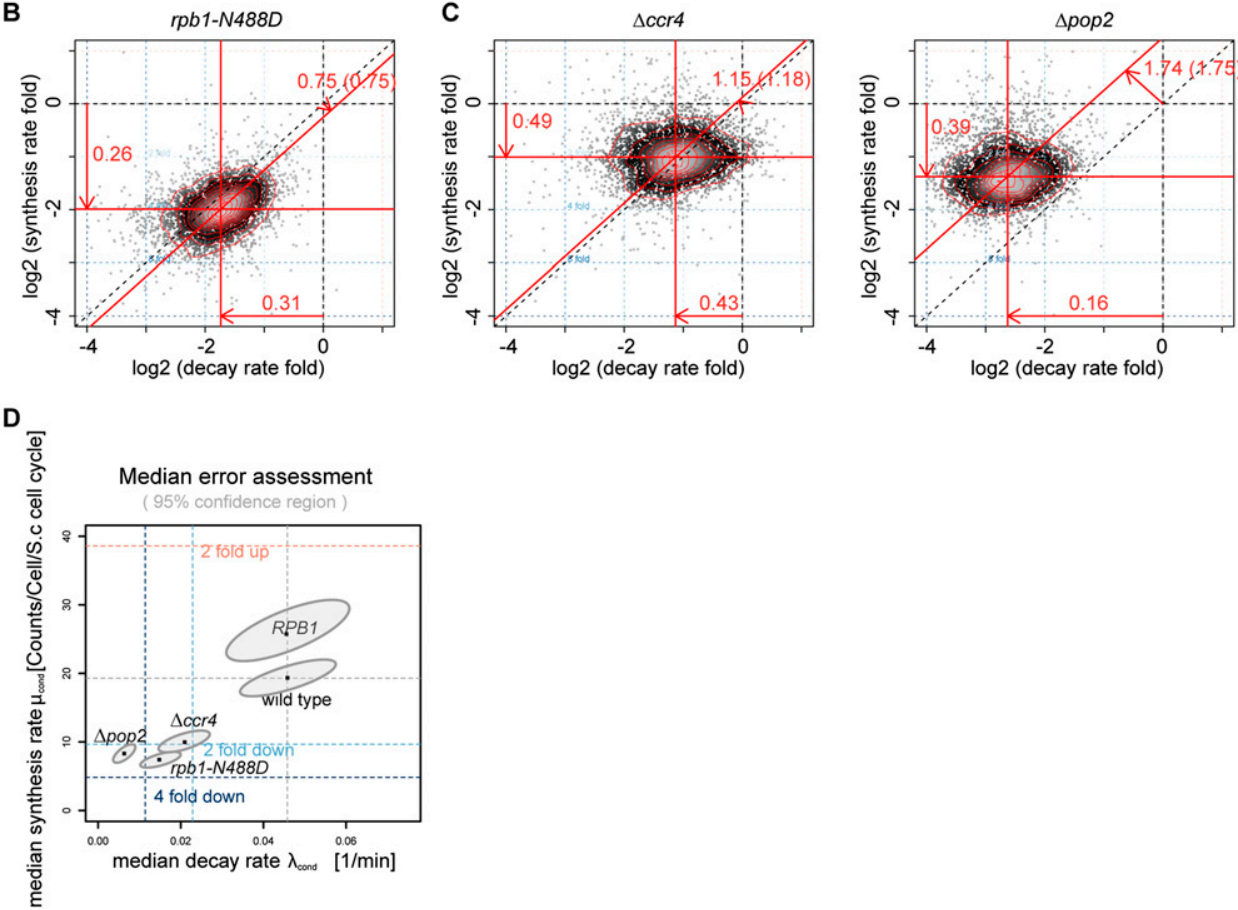

Figure 6. CDTA reveals changes in mRNA metabolism upon genetic perturbation. ( $A$ ) Linear scatter plots (heat-colored) of mRNA synthesis rates, decay rates, and total mRNA levels in wild-type and mutant rpb1-N488D yeast strains as measured by CDTA. Slopes indicate global shift ratios of median synthesis rates, decay rates, and total mRNA of the rpb1-N488D mutant strain compared with wild type $(0.26 / 0.31 / 0.75)$. (B) Alternative representation of the data from $A$ in a single scatter plot comparing the changes in mRNA synthesis rates (log folds, $x$-axis) and decay rates (log folds, $y$-axis) in the rpb 1-N488D mutant strain compared with the wild-type strain. Each point corresponds to one mRNA. The density of points is encoded by their brightness (grayscale). Contour lines define regions of equal density. The center of the distribution is located at $(-1.8,-1.6)$, indicating that there is a global shift in the median synthesis rate by a factor of 0.26 (shift of the horizontal red line relative to the dashed $x$-axis line), and a global shift in the median decay rate by a factor of 0.31 (shift of the vertical red line relative to the dashed $y$-axis line). The global change in total mRNA levels is predicted by the offset of the diagonal red line from the dashed main diagonal, which corresponds to a change by a factor of 0.75 . The number in brackets following this number $(0.75)$ is the global change as it has been observed in the total mRNA measurements, which agrees well with the predicted number. The changes in total RNA levels do not exactly equal the quotient of synthesis and decay rate changes, due to an additional parameter for cell growth. (C) Scatter plots as in $B$ comparing synthesis rates, decay rates, and total mRNA levels of $\Delta c c r 4$ and $\Delta$ pop 2 mutant strains to wild-type yeast. Ratios of median synthesis rates, decay rates, and total mRNA of the $\Delta c c r 4 / \Delta$ pop2 mutant strain compared with wild type are $0.49 / 0.39,0.43 / 0.16$, and $1.15 / 1.74$, respectively. $(D)$ Coupling of synthesis and decay rates, on the absolute level. For each condition, the median synthesis rate ( $y$-axis) and degradation rate ( $x$-axis) is shown (dark dots). (Dashed lines) Fold induction/repression relative to wild type. The dots lie approximately on a line with positive slope, indicating synthesis-decay compensation. A variation analysis for the estimation of the median synthesis and decay rates with cDTA has been performed. The ellipses show the $95 \%$ bootstrap confidence regions in each condition. The main axes of the ellipses reveal that the errors in the estimation of synthesis and decay rates are not independent, yet small enough to prove that the coupling is not due to estimation variance.

either one of the two catalytic subunits of the mRNA deadenylase complex Ccr4-Not showed not only the expected defect in mRNA degradation, but also a compensatory decrease in mRNA synthesis, also leading to a buffering of mRNA levels. This indicated the existence of a feedback loop that connects mRNA synthesis and degradation and serves to buffer mRNA levels. These results support published evidence for a global control of mRNA levels in dependence of cell size (Zhurinsky et al. 2010). This global control of
mRNA levels occurs despite the separation of mRNA synthesis and degradation into nuclear and cytoplasmic compartments.

The mechanisms underlying the synthesis-decay feedback loop and the buffering of mRNA levels are unclear. The feedback loop may be a result of a physical and functional coupling between the various parts of mRNA metabolism. Transcription is coupled to mRNA processing and export (Maniatis and Reed 2002), and translation is coupled to mRNA degradation (Coller and Parker

\section{Genome Research www.genome.org}


2004, 2005; Brengues et al. 2005; Hu et al. 2009). There is also evidence that nuclear and cytoplasmic mRNA metabolism are linked. The Pol II subcomplex Rpb4/7 shuttles between the nucleus and cytoplasm (Selitrennik et al. 2006) and is involved in transcription (Edwards et al. 1991) and mRNA translation and degradation (Lotan et al. 2005; Lotan et al. 2007; Harel-Sharvit et al. 2010). The Ccr4-Not complex is involved in mRNA degradation (Tucker et al. 2002) and also in transcription (Liu et al. 1998; Collart 2003; Collart and Timmers 2004; Kruk et al. 2011). From an extension of our kinetic model of mRNA turnover, we propose that the feedback loop is established by a factor that acts as degradation enhancer and a transcription inhibitor. It is thus unlikely that factors that act positively on transcription, such as Rpb4/7 and the Ccr4-Not complex, are the feedback factors, although the validity of our model's assumptions remains to be shown.

\section{Methods}

\section{Yeast strains and growth curves}

Strains RPB1 and rpb1-N488D (GRY 3020 and GRY 3027, respectively) were generously provided by Mikhail Kashlev (Malagon et al. 2006). Genotypes of GRY 3020 and GRY 3027 are MATa, his $3 \Delta 1$, leu2 $\Delta 0$, lys $2 \Delta 0$, met15 0 , trp1 $1::$ hisG, URA3::CMV-tTA RPO21, and MATa, his $3 \Delta 1$, leu2 $\Delta 0$, lys $2 \Delta 0$, met15 0 , trp1 $1::$ hisG, $U R A 3:: C M V$-tTA $r p b 1-N 488 D$. For cDTA we used $S c$ wild-type strain BY4741 MATa, his3 $\Delta 1$, leu2 $\Delta 0$, met15 $\Delta O$, ura3 $\Delta O$ (Euroscarf), and the isogenic knockout $\Delta p o p 2$ and $\Delta c c r 4 . \Delta p o p 2$ was from the YKO library (OpenBiosystem) and $\Delta c c r 4$ was generated by substituting the target gene for a KanMX cassette using homologous recombination in the same genetic background (Longtine et al. 1998). The $r p b 1-1$ (rpb1-G1437D) strain and isogenic wild-type strain were generated in our lab. Plasmids pRS316-RPO21, pRS315RPO21, and pRS315-rpb1-1 were generated by cloning the respective ORF or mutant ORF plus sequences $500 \mathrm{bp}$ upstream and 250 bp downstream into pRS316 (ATCC) and pRS315 (ATCC) using XhoI/SacI restriction sites. The heterozygous RPO21/rpo21 $S c$ yeast strain (BY4743, rpo21::KanMX6/RPO21) was generated and transformed with pRS316-RPO21. Diploids were sporulated and tetrads dissected on YPD plates. After transformation of the shuffle strains with pRS315-RPO21 or pRS315-rpb1-1, the resulting strains were streaked twice on 5-FOA plates and then on SC-Leu. Sp strain FY2317 h+, leu1-32::hENT1-leu1+(pJAH29) his7-366:: hsv-tkhis7+(pJAH31) ura4-D18 ade6-M210 (Hodson et al. 2003) was kindly provided by Susan Forsburg. YPD medium was inoculated with a single $S c$ colony. $S p$ was grown in YES medium. The culture was grown to stationary phase overnight and diluted to $\mathrm{OD}_{600}=0.1$. Measure points were taken every hour before $\mathrm{OD}_{600}$ reached 3 . Additional time points were taken until stationary phase was reached. Doubling time was calculated by fitting the log-transformed values of $\mathrm{OD}_{600}$ into a linear function.

\section{Comparative dynamic transcriptome analysis (cDTA)}

$S c$ cells were grown in YPD medium overnight, diluted to an $\mathrm{OD}_{600}$ of 0.1 , and grown to mid-log phase. $\mathrm{OD}_{600}$ of 0.8 corresponded to $1.75 \times 10^{7}$ cells per mL. 4-thiouracil (4-tU, Sigma, $2 \mathrm{M}$ in DMSO) was added to the media at a final concentration of $5 \mathrm{mM}$, and cells were harvested after $6 \mathrm{~min}$ of labeling by centrifugation at $2465 \mathrm{~g}$ and $30^{\circ} \mathrm{C}$ for $1 \mathrm{~min}$. The supernatant was discarded and the pellet resuspended in RNAlater solution (Ambion/Applied Biosystems). The cell concentration was determined by Cellometer N10 (Nexus) before flash-freezing in liquid nitrogen. $S p$ cells were grown in YES medium overnight, diluted to $\mathrm{OD}_{600}=0.1$, and grown to $\mathrm{OD}_{600}=$ 0.8 . $4 \mathrm{sU}$ was solved in $\mathrm{ddH}_{2} \mathrm{O}(50 \mathrm{mM})$ and added to a final concentration of $500 \mu \mathrm{M}$, and cells were labeled for $6 \mathrm{~min}$. Cells were harvested by centrifugation at $2465 \mathrm{~g}$ for $3 \mathrm{~min}$. Other steps were as above. A 4-liter-culture of $S p$ cells was labeled to generate a stock and eliminate errors by variations in the standard. Cells were counted as above. $S p$ cells were mixed with $S c$ cells in a 1:3 ratio, resulting in $4 \times 10^{8}$ cells in total. Total RNA extraction, labeled RNA purification, as well as sample hybridization and microarray scanning were as previously described (Miller et al. 2011). For the cDTA analysis of $r p b 1-1$ strains, overnight cultures were diluted in fresh medium to an $\mathrm{OD}_{600}$ of $0.15(125 \mathrm{~mL}$ cultures, $160 \mathrm{rpm}$ shaking incubator, $30^{\circ} \mathrm{C}$ ). At an $\mathrm{OD}_{600}$ of 0.9 (time point: $18 \mathrm{~min}$ ), RNA was labeled. Eighteen minutes later (time point $0 \mathrm{~min}$ ) cultures were shifted to $37^{\circ} \mathrm{C}$ by adding the same volume of $42^{\circ} \mathrm{C}$ tempered medium. RNA was again labeled $18 \mathrm{~min}$ and $60 \mathrm{~min}$ after heat shock (time points $+24 \mathrm{~min}$ and $+66 \mathrm{~min}$, respectively).

\section{cDTA data analysis}

Data was preprocessed arraywise using expresso (R/Bioconductor) with the RMA background correction method. We created our own probe annotation environment (cdf), which excludes probes in probesets that show cross-hybridization between $S c$ and $S p$. A total of 8708 annotated $S c$ probes and 13,317 annotated $S p$ probes out of a total of 120,855 probes showed cross-hybridization when a conservative intensity cut-off of 4.5 (log intensity values after preprocessing) was used. Cross-hybridizing probes were excluded from further analysis. This included 16 whole probe sets (Fig. 2A; see Supplemental Fig. S1). Note that the standard GC-RMA method is not suitable for our purposes since its bias model cannot handle bimodal intensity distributions, as caused by the simultaneous hybridization of $S c$ and $S p$ transcripts with global differences in RNA abundance (Fig. 2B). Labeling bias estimation and correction was done as described (Miller et al. 2011) (Supplemental Methods S9). Between-array normalization of arrays containing mixed Sc and $S p$ total RNA was done by proportional rescaling, such that the median $S p$ gene expression level was 1 (Fig. 3B). Accordingly, between-array normalization of arrays containing mixed $S c$ and $S p$ labeled RNA was done by proportionally scaling the array to a median-labeled $S p$ gene expression level of $c$ (Fig. 3A). The constant $c$ scales the median half-life of all experiments. We calibrated $c$ in a way that the resulting median $S c$ wild-type mRNA half-life equaled that observed previously (Miller et al. 2011). Now, all $S c$ RNA levels, no matter whether total or labeled, no matter from which experiment, can be compared on an absolute level. Decay rates and synthesis rates were obtained as described (Miller et al. 2011; Supplemental Methods S9). We assume that the labeled RNA fraction is subject to degradation from the very time it is synthesized. In contrast, Rabani et al. 2011 (see Supplemental Methods therein) assume that the labeled RNA fraction is mostly nuclear and not degraded at all. We compared the synthesis rate estimates resulting from both alternatives (Supplemental Methods S9). Given our labeling time, the differences of both approaches are negligible. The whole analysis workflow has been carried out using the open source R/Bioconductor package DTA (Schwalb et al. 2012).

\section{Calculation of 4tU incorporation efficiency}

The metabolic labeling efficiency $p_{\text {lab }}$ is defined as $p_{l a b}=p_{\text {inc }} \cdot p_{c a p}$, the product of the incorporation efficiency $p_{i n c}$ (the probability of $4 \mathrm{tU}$ for being incorporated into an RNA transcript instead of a uridine) and the capture efficiency $p_{\text {cap }}$ (the probability of a $4 \mathrm{tU}$ 
nucleotide inside an RNA for being biotinylated, captured, and recovered from streptavidin beads). A labeling efficiency substantially below 1 introduces a uridine-dependent labeling bias by letting newly transcribed, uridine-poor RNA have a higher probability to escape labeling. All of these efficiencies are of experimentand strain-specific quantities. Only $p_{\text {lab }}$ can be estimated directly from cDTA data (Supplemental Method S10). We can use cDTA to conclude from $p_{\text {lab }}$ to the relative incorporation efficiencies by the equation

$$
\frac{p_{\text {inc }}(x, S c)}{p_{\text {inc }}(y, S c)}=\frac{p_{l a b}(x, S c)}{p_{l a b}(x, S p)} \cdot\left(\frac{p_{l a b}(y, S c)}{p_{l a b}(y, S p)}\right)^{-1} .
$$

\section{RT-qPCR}

$S p$ and $S c$ cells were grown to $\mathrm{OD}_{600}=0.8$, harvested, and flashfrozen in liquid nitrogen. Cells were counted and mixed at 1:1 and 10:1 ratios. Total RNA was extracted, and the mRNA levels of $S c$ genes ACT1(YFLO39C), ADH1(YOLO86C), HIS4(YCLO3OC), and RDN1 (rRNA locus) and Sp genes GDI1(SPAC22H1O.12c) and GPD1(SPBC215.05) were determined by RT-qPCR. RT-qPCR was carried out as described (Miller et al. 2011). A total of $500 \mathrm{ng}$ of RNA was used to reverse transcribe cDNA using the iScript cDNA Synthesis Kit (BioRad). Primers were designed with the ProbeFinder online tool (http://qpcr.probefinder.com/organism.jsp, Roche Applied Science). The primer-pair efficiency was tested individually and ranged between $97 \%$ and $100 \%$. PCR reactions contained $1 \mu \mathrm{L}$ of DNA template, $2 \mu \mathrm{L}$ of $10 \mu \mathrm{M}$ primer pairs, and $12.5 \mu \mathrm{L}$ of SsoFast EvaGreen Supermix (BioRad). qPCR was performed on a Bio-Rad CFX96 Real-Time System (Bio-Rad Laboratories, Inc.) using a 30-sec denaturing step at $95^{\circ} \mathrm{C}$, followed by 40 cycles of $1 \mathrm{sec}$ at $95^{\circ} \mathrm{C}, 4 \mathrm{sec}$ at $63^{\circ} \mathrm{C}$. Data analysis was performed with the software Bio-Rad CFX Manager 1.6.

\section{Kinetic model}

Our model has been cast as Equation (1) provided in the main text. The steady-state mRNA levels predicted by this model are $g=\frac{\mu_{g}}{\lambda_{g}} \cdot \frac{f(s)}{h(d)}$, from which we deduce that regulation imposed by $\mathrm{S}$ or $\mathrm{D}$ is always global, i.e., total mRNA levels are shifted by a common factor $f(s) / h(d)$. Since the mRNA levels in the deadenylation mutants globally increase, we conclude that the mRNA level $s^{\prime}$ of $S$ in the deadenylation mutants is higher than in wild-type (level $s$ ). At the same time, we can estimate the quotient $f\left(s^{\prime}\right) / f(s)$ by

$$
\begin{aligned}
\frac{f\left(s^{\prime}\right)}{f(s)} & =\text { median }\left(\frac{\text { synthesis rate of } g \text { in the mutant }}{\text { synthesis rate of } g \text { in the wildtype }}, g \in \text { genes }\right) \\
& =\left\{\begin{array}{l}
0.4 \text { for } \Delta \text { pop } 2 \\
0.5 \text { for } \Delta c c r 4
\end{array}<1\right.
\end{aligned}
$$

(see Supplemental Fig. S8 for a rigorous derivation). Together, $s^{\prime}>s$ and $f\left(s^{\prime}\right)<f(s)$ imply that $f$ acts as a transcription inhibitor. Similar considerations show that $d^{\prime}<d$ holds in the Pol II mutant, and that

$$
\begin{aligned}
& \frac{h\left(d^{\prime}\right)}{h(d)}=\frac{\text { total mRNA mutant }}{\text { total mRNA wildtype }} \\
& \text {-median }\left(\frac{\text { decay rate of } \mathrm{g} \text { in the mutant }}{\text { decay rate of } \mathrm{g} \text { in the wildtype }}, g \in \text { genes }\right)=0.31<1 \text {. }
\end{aligned}
$$

From $d^{\prime}<d$ and $h\left(d^{\prime}\right)<h(d)$ we conclude that $\mathrm{D}$ is a degradation enhancer.

\section{Data access}

Microarray data were deposited in ArrayExpress (http://www.ebi. ac.uk/arrayexpress/) under accession number E-MTAB-760.

\section{Acknowledgments}

We thank the members of the Tresch and Cramer laboratories. We thank Dr. Elisabeth Lehmann for generating the heterozygote shuffle strain RPO21/rpo21. A.T. was supported by the LMUexcellent guest professorship "Computational Biochemistry." P.C. was supported by the Deutsche Forschungsgemeinschaft, SFB646, TR5, FOR1068, NIM, the European Molecular Biology Organization (EMBO), an Advanced Investigator Grant of the European Research Council, a LMUexcellent research professorship "Molecular systems biology of gene regulation," the LMUinnovativ project Bioimaging Network (BIN), and the Jung-Stiftung.

Author contributions: M. Sun, B.S., L.L., and P.C. conceived and designed the study. M. Sun and D.S. implemented and evaluated experimental methods. S.E. and M. Seizl conducted the rpb1-1 experiments. B.S. and A.T. designed and carried out computational analyses. M.S., D.S., N.P., K.M., S.E., and M. Seizl designed and performed experiments. P.C. and A.T wrote the manuscript, with input from all authors. M. Sun, B.S., and D.S. contributed equally.

\section{References}

Amorim MJ, Cotobal C, Duncan C, Mata J. 2010. Global coordination of transcriptional control and mRNA decay during cellular differentiation. Mol Syst Biol 6: 380. doi: 10.1038/msb.2010.38.

Bauer S, Gagneur J, Robinson PN. 2010. GOing Bayesian: Model-based gene set analysis of genome-scale data. Nucleic Acids Res 38: 3523-3532.

Brengues M, Teixeira D, Parker R. 2005. Movement of eukaryotic mRNAs between polysomes and cytoplasmic processing bodies. Science 310: 486-489.

Collart MA. 2003. Global control of gene expression in yeast by the Ccr4Not complex. Gene 313: 1-16.

Collart MA, Timmers HTM. 2004. The eukaryotic Ccr4-Not complex: A regulatory platform integrating mRNA metabolism with cellular signaling pathways? Prog Nucleic Acid Res Mol Biol 77: 289-322.

Coller J, Parker R. 2004. Eukaryotic mRNA decapping. Annu Rev Biochem 73: 861-890.

Coller J, Parker R. 2005. General translational repression by activators of mRNA decapping. Cell 122: 875-886.

Cramer P, Bushnell DA, Kornberg RD. 2001. Structural basis of transcription: RNA polymerase II at 2.8 Ångstrom resolution. Science 292: 1863-1876.

Dori-Bachash M, Shema E, Tirosh I. 2011. Coupled evolution of transcription and mRNA degradation. PLoS Biol 9: e1001106. doi: 10.1371/journal.pbio.1001106.

Edwards AM, Kane CM, Young RA, Kornberg RD. 1991. Two dissociable subunits of yeast RNA polymerase II stimulate the initiation of transcription at a promoter in vitro. J Biol Chem 266: 71-75.

Eulalio A, Behm-Ansmant I, Izaurralde E. 2007. P bodies: At the crossroads of post-transcriptional pathways. Nat Rev Mol Cell Biol 8: 9-22.

Fuda NJ, Ardehali MB, Lis JT. 2009. Defining mechanisms that regulate RNA polymerase II transcription in vivo. Nature 461: 186-192.

Grigull J, Mnaimneh S, Pootoolal J, Robinson MD, Hughes TR. 2004. Genome-wide analysis of mRNA stability using transcription inhibitors and microarrays reveals posttranscriptional control of ribosome biogenesis factors. Mol Cell Biol 24: 5534-5547.

Harel-Sharvit L, Eldad N, Haimovich G, Barkai O, Duek L, Choder M. 2010. RNA polymerase II subunits link transcription and mRNA decay to translation. Cell 143: 552-563.

Hekstra D, Taussig AR, Magnasco M, Naef F. 2003. Absolute mRNA concentrations from sequence-specific calibration of oligonucleotide arrays. Nucleic Acids Res 31: 1962-1968.

Held GA, Grinstein G, Tu Y. 2003. Modeling of DNA microarray data by using physical properties of hybridization. Proc Natl Acad Sci 100: 7575-7580.

Held GA, Grinstein G, Tu Y. 2006. Relationship between gene expression and observed intensities in DNA microarrays-a modeling study. Nucleic Acids Res 34: e70. doi: 10.1093/nar/gkl122.

Hereford LM, Rosbash M. 1977. Regulation of a set of abundant mRNA sequences. Cell 10: 463-467.

Hodson JA, Bailis JM, Forsburg SL. 2003. Efficient labeling of fission yeast Schizosaccharomyces pombe with thymidine and BUdR. Nucleic Acids Res 31: e134. doi: 10.1093/nar/gng137.

Holstege FCP, Jennings EG, Wyrick JJ, Lee TI, Hengartner CJ, Green MR, Golub TR, Lander ES, Young RA. 1998. Dissecting the regulatory circuitry of a eukaryotic genome. Cell 95: 717-728. 
Houseley J, Tollervey D. 2009. The many pathways of RNA degradation. Cell 136: $763-776$.

$\mathrm{Hu}$ W, Sweet TJ, Chamnongpol S, Baker KE, Coller J. 2009. Co-translational mRNA decay in Saccharomyces cerevisiae. Nature 461: 225-229.

Jimeno-González S, Haaning LL, Malagon F, Jensen TH. 2010. The yeast 5' -3' exonuclease Rat1p functions during transcription elongation by RNA polymerase II. Mol Cell 37: 580-587.

Jorgensen P, Nishikawa JL, Breitkreutz B-J, Tyers M. 2002. Systematic identification of pathways that couple cell growth and division in yeast. Science 297: 395-400.

Kruk JA, Dutta A, Fu J, Gilmour DS, Reese JC. 2011. The multifunctional Ccr4-Not complex directly promotes transcription elongation. Genes Dev 25: 581-593.

Liu H-Y, Badarinarayana V, Audino DC, Rappsilber J, Mann M, Denis CL. 1998. The NOT proteins are part of the CCR4 transcriptional complex and affect gene expression both positively and negatively. EMBO J 17: 1096-1106.

Longtine MS III, Demarini AM, Shah DJ, Wach NG, Brachat A, Philippsen A Pringle P Jr. 1998. Additional modules for versatile and economical PCRbased gene deletion and modification in Saccharomyces cerevisiae. Yeast 14: $953-961$.

Lotan R, Bar-On VG, Harel-Sharvit L, Duek L, Melamed D, Choder M. 2005 The RNA polymerase II subunit Rpb4p mediates decay of a specific class of mRNAs. Genes Dev 19: 3004-3016.

Lotan R, Goler-Baron V, Duek L, Haimovich G, Choder M. 2007. The Rpb7p subunit of yeast RNA polymerase II plays roles in the two major cytoplasmic mRNA decay mechanisms. J Cell Biol 178: 1133-1143.

Malagon F, Kireeva ML, Shafer BK, Lubkowska L, Kashlev M, Strathern JN. 2006. Mutations in the Saccharomyces cerevisiae RPB1 gene conferring hypersensitivity to 6-azauracil. Genetics 172: 2201-2209.

Maniatis T, Reed R. 2002. An extensive network of coupling among gene expression machines. Nature 416: 499-506.

Miller C, Schwalb B, Maier K, Schulz D, Dumcke S, Zacher B, Mayer A, Sydow J, Marcinowski L, Dolken L, et al. 2011. Dynamic transcriptome analysis measures rates of mRNA synthesis and decay in yeast. Mol Syst Biol 7: 458. doi: $10.1038 / \mathrm{msb} 2010.112$.

Munchel SE, Shultzaberger RK, Takizawa N, Weis K. 2011. Dynamic profiling of mRNA turnover reveals gene-specific and system-wide regulation of mRNA decay. Mol Biol Cell 22: 2787-2795.

Neumann FR, Nurse P. 2007. Nuclear size control in fission yeast. J Cell Biol 179: $593-600$.

Nonet M, Scafe C, Sexton J, Young R. 1987. Eucaryotic RNA polymerase conditional mutant that rapidly ceases mRNA synthesis. Mol Cell Biol 7: 1602-1611.

Parker R, Sheth U. 2007. P bodies and the control of mRNA translation and degradation. Mol Cell 25: 635-646.
Rabani M, Levin JZ, Fan L, Adiconis X, Raychowdhury R, Garber M, Gnirke A, Nusbaum C, Hacohen N, Friedman N, et al. 2011. Metabolic labeling of RNA uncovers principles of RNA production and degradation dynamics in mammalian cells. Nat Biotechnol 29: 436-442.

Schwalb B, Schulz D, Sun M, Zacher B, Dümcke S, Martin DE, Cramer P, Tresch A. 2012. Measurement of genome-wide RNA synthesis and decay rates with Dynamic Transcriptome Analysis (DTA). Bioinformatics 28: $884-885$.

Selitrennik M, Duek L, Lotan R, Choder M. 2006. Nucleocytoplasmic shuttling of the Rpb4p and Rpb7p subunits of Saccharomyces cerevisiae RNA polymerase II by two pathways. Eukaryot Cell 5: 2092 2103.

Shalem O, Dahan O, Levo M, Martinez MR, Furman I, Segal E, Pilpel Y. 2008. Transient transcriptional responses to stress are generated by opposing effects of mRNA production and degradation. Mol Syst Biol 4: 4. doi: 10.1038/msb.2008.59.

Skvortsov D, Abdueva D, Curtis C, Schaub B, Tavaré S. 2007. Explaining differences in saturation levels for Affymetrix GeneChip arrays. Nucleic Acids Res 35: 4154-4163.

Tucker M, Valencia-Sanchez MA, Staples RR, Chen J, Denis CL, Parker R. 2001. The transcription factor associated Ccr4 and Caf1 proteins are components of the major cytoplasmic mRNA deadenylase in Saccharomyces cerevisiae. Cell 104: $377-386$.

Tucker M, Staples RR, Valencia-Sanchez MA, Muhlrad D, Parker R. 2002. Ccr4p is the catalytic subunit of a Ccr4p/Pop2p/Notp mRNA deadenylase complex in Saccharomyces cerevisiae. EMBO J 21: 1427 1436.

van de Peppel J, Kemmeren P, van Bakel H, Radonjic M, van Leenen D, Holstege FC. 2003. Monitoring global messenger RNA changes in externally controlled microarray experiments. EMBO Rep 4: 387393.

Wang Y, Liu CL, Storey JD, Tibshirani RJ, Herschlag D, Brown PO. 2002. Precision and functional specificity in mRNA decay. Proc Natl Acad Sci 99: 5860-5865.

Wiederhold K, Passmore LA. 2010. Cytoplasmic deadenylation: Regulation of mRNA fate. Biochem Soc Trans 38: 1531-1536.

Zenklusen D, Larson DR, Singer RH. 2008. Single-RNA counting reveals alternative modes of gene expression in yeast. Nat Struct Mol Biol 15: 1263-1271.

Zhurinsky J, Leonhard K, Watt S, Marguerat S, Bähler J, Nurse P. 2010. A coordinated global control over cellular transcription. Curr Biol 20: 2010-2015.

Received August 2, 2011; accepted in revised form March 19, 2012. 


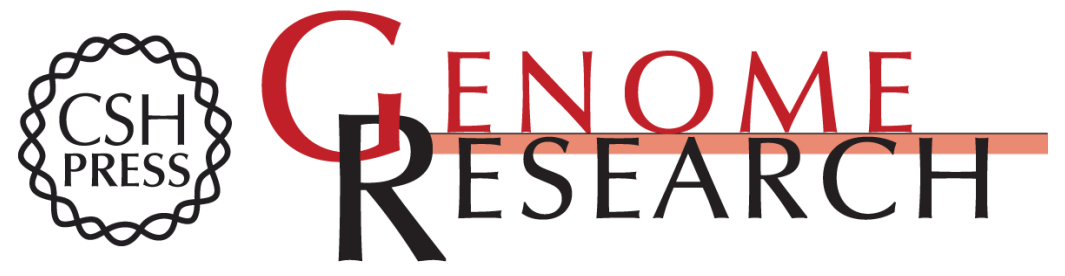

\section{Comparative dynamic transcriptome analysis (cDTA) reveals mutual feedback between mRNA synthesis and degradation}

Mai Sun, Björn Schwalb, Daniel Schulz, et al.

Genome Res. 2012 22: 1350-1359 originally published online March 30, 2012

Access the most recent version at doi:10.1101/gr.130161.111

Supplemental Material

References

Creative

Commons

License

Email Alerting

Service
http://genome.cshlp.org/content/suppl/2012/03/21/gr.130161.111.DC1

This article cites 48 articles, 19 of which can be accessed free at: http://genome.cshlp.org/content/22/7/1350.full.html\#ref-list-1

This article is distributed exclusively by Cold Spring Harbor Laboratory Press for the first six months after the full-issue publication date (see

http://genome.cshlp.org/site/misc/terms.xhtml). After six months, it is available under a Creative Commons License (Attribution-NonCommercial 3.0 Unported License), as described at http://creativecommons.org/licenses/by-nc/3.0/.

Receive free email alerts when new articles cite this article - sign up in the box at the top right corner of the article or click here.

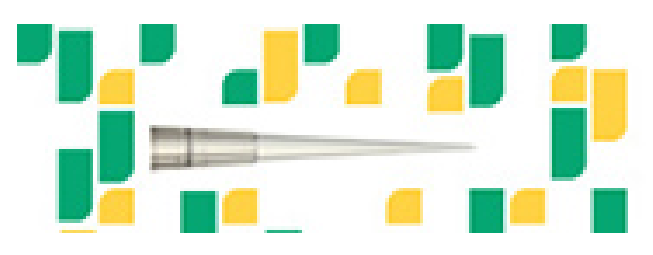

Focused on your science.

Jコగ

SCIENTIFIC

suos or seisnes

To subscribe to Genome Research go to: https://genome.cshlp.org/subscriptions 